University of Nebraska - Lincoln

DigitalCommons@University of Nebraska - Lincoln

To Improve the Academy

Professional and Organizational Development Network in Higher Education

1998

Supporting Faculty Development in an Era of Change

Carol Fulton

Barbara L. Licklider

Follow this and additional works at: https://digitalcommons.unl.edu/podimproveacad

Part of the Higher Education Administration Commons

Fulton, Carol and Licklider, Barbara L., "Supporting Faculty Development in an Era of Change" (1998). To Improve the Academy. 402.

https://digitalcommons.unl.edu/podimproveacad/402

This Article is brought to you for free and open access by the Professional and Organizational Development Network in Higher Education at DigitalCommons@University of Nebraska - Lincoln. It has been accepted for inclusion in To Improve the Academy by an authorized administrator of DigitalCommons@University of Nebraska - Lincoln. 
Fulton, C., \& Licklider, B. L. (1998). Supporting faculty development in an era of change. In M. Kaplan (Ed.), To Improve the Academy, Vol. 17 (pp. 51-66). Stillwater, OK: New Forums Press and the Professional and Organizational Development Network in Higher Education. Key Words: active learning, faculty development, faculty development programs.

\section{Supporting Faculty \\ Development in an Era of Change}

\section{Carol Fulton}

\section{Barbara L. Licklider}

Iowa State University

A paradigm shift is underway in higher education. Realizing the hoped-for gains of new student-centered approaches will require significantly different approaches to faculty development. This paper describes one such approach to faculty development and how it is currently being used to improve the learning and teaching experience in the College of Engineering at a land grant institution in the Midwest. Considerations for the widespread application of this approach are also offered.

A paradigm shift in college teaching is underway (Barr \& Tagg, 1995; Campbell \& Smith, 1997). Recognizing that old ways (which no longer work for new needs) must yield to change, colleges and universities are gradually replacing the old "telling" paradigm with new "learner-centered" approaches to instruction.

These new approaches have significantly raised expectations for student achievement and institutional quality-areas long deemed 
inadequate by industry, government leaders, and the public (Study Group on the Condition of Excellence in American Higher Education, 1984; Association of American Colleges, 1985; National Science Foundation, 1996). Realizing these gains, however, depends ultimately on faculty learning this new vision of practice, a vision that is significantly different from the old vision that faculty experienced as students and that subsequently dominates their practice.

Seen in this light, faculty development is the linchpin to student development. Significant improvements in the quality of higher education hinge on considerable investment in faculty; however, the current situation calls for a different kind of faculty development. Just as the complex outcomes now desired for students (e.g., critical thinking, problem solving, the ability to see from diverse perspectives) cannot be taught directly via the telling paradigm, so too, the knowhow to affect these outcomes cannot simply be "given" to faculty by means of traditional faculty development practices (e.g., newsletters, one-shot workshops ). Instead, new structures are needed that provide opportunities for faculty to reflect critically on their practice and to fashion new understandings about learning and teaching.

Project LEA/RN ${ }^{\mathrm{TM}}$ (Learning Enhancement Action/Resource Network) was designed to begin to address these concerns. Based on a model consistent with current views of practice and research, Project LEA/RN ${ }^{\mathrm{TM}}$ was created to improve teaching and learning in the College of Engineering at a land grant institution in the Midwest. This article describes the implementation of Project LEA/RN ${ }^{\mathrm{TM}}$. The discussion unfolds in three sections. The first section describes the theoretical roots that form the basis for this work. The second section details the implementation of the model in Project LEA/RN ${ }^{\mathrm{TM}}$. The article concludes with implications of this work for widespread change of undergraduate education.

\section{Project Underpinnings}

The model upon which Project LEA/RN ${ }^{\mathrm{TM}}$ is built is depicted in Figure 1. The model is a synthesis of research, theory, and implications for practice drawn from the fields of cognitive psychology and staff development. New insights about learning derived from recent work 
in cognitive psychology coupled with structures and strategies derived from staff development research provide the foundation and framework needed for reconfiguring faculty development. A detailed description of the development of the model can be found in Licklider, Schnelker, \& Fulton (1998). A brief summary of the project underpinnings is presented below.

\section{The Nature of Learning}

Project LEA/RN ${ }^{\mathrm{TM}}$ embraces an active view of learning. This perspective, grounded in two decades of research in cognitive psychology, has changed what we know about learning and learners (von Glaserfeld, 1983; Brookfield, 1988; Mezirow, 1991; Svinicki, 1991; Leinhardt, 1992). From this perspective:

Learners are not passive recipients of knowledge; they actively construct, modify, or enrich their understandings. "Learning is something that the learner does, not something that is done to a learner"(Johnson, Johnson, \& Smith, 1991, pp. 1-7). This perspective, which emphasizes the active participation of learners in constructing their own knowledge, stands in sharp contrast to models that see the learner as the receiver of knowledge from the instructor or curriculum.

Learners have prior knowledge that affects how they perceive and understand the world. Learning theorists have documented the critical role that prior knowledge plays in learners' construction of new understandings. Who they are, what they do, where they have been, and what they expect, all affect how students construct meaning and interpret new concepts.

Reflection is crucial to learning. Students' prior perspectives may contain gaps or flaws. It is through the process of critical reflection that learners become aware of gaps, challenge underlying assumptions, and potentially reconstruct their understandings.

Learning is social and interactive. New views emphasize the social nature of learning. Not only do individuals actively construct knowledge, but so, too, do groups to which individuals belong. These shared definitions allow members to work towards group goals. These processes of individual and social construction of knowledge occur simultaneously and are interactive in nature. 


\section{Implications for Teaching}

This new view of learning significantly changes what faculty must do to enable learning. Based on the nature of learning, teaching should emphasize:

Processes that allow students to construct, transform, and extend their knowledge. Learners act on information to make it meaningful by creating connections, discovering relationships, and formulating and reformulating patterns. Consequently, students need to be actively engaged, not in the memorization of facts, but in representing their ideas, giving explanations, challenging and defending solutions, and exploring further implications. To enable students to take these effective actions, faculty now must design tasks, model problem-solving actions, provide feedback on performance, challenge prior beliefs, and manage and focus discussion as needed.

Content that allows students to construct, transform, and extend their knowledge. Learning is the continual reworking and refinement of ideas. Authentic tasks, grounded in real-world experiences known to students enable them to build on prior knowledge. Activities which incorporate the use of new ideas in a wide variety of contexts develop higher level thinking and enable transfer to new situations. As facilitators of students' learning, faculty raise questions that push understandings to deeper levels, explore commonsense misconceptions with the goal of developing deeper insights, and help students bridge between existing knowledge and new situations.

Structures that allow students to construct, transform, and extend their knowledge. Learning occurs best through communication and cooperation with others. To this end, activities are frequently structured in pairs and small groups in addition to individual activities and whole group discussion. Drawing on prior knowledge to solve real-world problems while working with others provides a natural bridge for critical self-reflection of ideas and consequent cognitive reorganization. No longer sole judge and authority of knowledge, faculty now are co-collaborators in the social construction of knowledge. 


\section{Considerations for Faculty Development}

New visions of learning and teaching and new views of professional development go hand in hand. Drawing on this link, the following ideas served to guide Project LEA/RN ${ }^{\mathrm{TM}}$ :

Teaching should be grounded in the students' experience of learning. Many traditional faculty development efforts provide tips and strategies faculty may use without paying sufficient attention to the underlying assumptions upon which practice is based (Cranton, 1994; Brookfield, 1995). Such efforts result in little, if any, change. Project LEA/RN ${ }^{\mathrm{TM}}$ is based on the assumption that the key to improving instruction lies in understanding the learning process itself. As faculty grow in their understanding of their students' experience of learning, they are better able to teach responsively.

Faculty are learners. What is good for students is good for faculty. Faculty, like their students, learn by reading, experiencing, reflecting, and collaborating with others. New insights cannot simply be given to them. Rather, faculty must engage in activities that cause them to reflect on what they do and why they do it. Such critical reflection about practice leads potentially to the transformation of previously held beliefs.

Acknowledging the preference for self-directedness of learners (Knowles, 1984; Candy, 1991), Project LEA/RN'M is guided by three additional principles: first, faculty want to be effective teachers; second, faculty will devote time and effort to improve the effectiveness of their teaching; and finally, given the opportunity and support, faculty will make rapid progress in enhancing their teaching effectiveness.

Content, processes, and structures should support faculty learning. New visions of professional development suggest that the practices needed to support faculty learning are analogous to those needed to support student learning. Such practices engage faculty as learners and participants in creating new understandings about learners, curriculum, and pedagogy; provide authentic opportunities to learn by connecting activities to the concrete tasks of teaching; and are carried out collaboratively, drawing on participants' experiences to solve practical problems and produce new knowledge. Furthermore, 
such practices make faculty development ongoing, allow sufficient time for experimentation and reflection, and are supported by modeling, collective feedback, and coaching.

At the heart of Project LEA/RN ${ }^{\mathrm{TM}}$ is the aim of immersing faculty in educational environments to build strong, ongoing support groups among faculty and to sustain long lasting change. Activities are designed to give faculty the opportunity to experiment with new strategies, provide feedback on revised practice, and encourage continued discussions about teaching and learning.

\section{Implementation}

This section describes the operationalization of the model as implemented in Project LEA/RN ${ }^{\mathrm{TM}}$. While described here under separate headings (structure, content, and process) for the purpose of illustrating the model, these elements in practice are interwoven as will be apparent throughout the discussion.

\section{Structure}

The main goals of Project LEA/RN ${ }^{\mathrm{TM}}$ are two-fold: 1) to encourage faculty to approach instruction purposefully and 2) to promote attitudes favorable towards student-centered approaches to learning. Participation in the project is voluntary. Feedback associated with participation in the program is independent of the formal faculty review process. Participants play an active role in the planning and direction of the program. In addition, faculty are encouraged to co-facilitate sessions and serve as resources for one another.

The role of the instructional developer is to facilitate faculty learning. The developer wears many hats during this process (e.g., designing activities, challenging faculty assumptions, lending expertise, etc.) with the ultimate goal of shifting expertise, control and decision-making to the faculty. While not dictating what faculty should do in their classrooms, project staff operate from a student-centered instructional mode when facilitating sessions.

Faculty meet in two-hour large group sessions every two weeks throughout the academic year. This format provides opportunity for demonstration, stimulates ongoing discussion about teaching and 
learning, and fosters an atmosphere of trust that comes from working together over time. Such an environment provides a safe, stimulating context in which to challenge assumptions, experiment with new behaviors, receive feedback on revised practices, and share classroom experiences (both victories and struggles) with colleagues.

Between bi-weekly large group meetings, faculty participate in expanded learning opportunities. In base groups of three to four, faculty read and discuss articles related to teaching and learning, discuss issues and concerns, and help each other plan to implement strategies learned in large group sessions. When comfortable, faculty pair as learning partners, observing each other's classes on a regular basis, participating in pre- and post-observation conferences, and providing support and non-evaluative feedback and reflection during the learning process.

\section{Content}

The content of Project LEA/RN ${ }^{\mathrm{TM}}$ connects to and stems from participants' actual classroom concerns. These concerns have evolved into a core set of four thrusts (engagement strategies, questioning strategies, lesson planning, and assessment) around which the biweekly meetings are organized throughout the course of the academic year. Early sessions introduce participants to active learning strategies such as Turn to Your Partner (TTYP), Problem Solving Pairs, and Student Base Groups (Johnson, Johnson, \& Smith, 1991). Faculty also study effective group functioning.

As professors work to incorporate these strategies into their courses, they discover that the "quality" of the questions they ask play a significant role in promoting (or failing to promote) interaction among students. This leads naturally to the second thrust. Through a number of activities, faculty examine the relationship between the types of questions they ask and the type of learning required by students. Faculty work on developing questions that provide higher level thinking (See Bloom in Gronlund, 1985 ) and good classroom interaction. During sessions, project staff model a number of strategies including wait time and inductive strategies. 
The key focus in the third thrust is lesson planning. Faculty work to develop learning outcomes, activities, and lesson sequences that are conducive to student-centered learning. The final thrust introduces faculty to classroom assessment techniques such as the Minute Paper and the Muddiest Point (Angelo \& Cross, 1993). Each of the thrusts is designed and presented to establish a knowledge base in learning theory, develop an array of progressively more effective teaching strategies, and foster ongoing discussion about teaching and learning.

While these four thrusts reflect the core content, LEA/RN is also guided by the philosophy of "begin where faculty are" and "go where faculty want to go." This means that the four thrusts are presented "roughly" as described, paced to meet participant needs. In addition, the developer has the added responsibility of balancing the four thrusts with the interests of faculty, supplementing them as needed with additional materials or topics.

\section{Process}

Project LEA/RN ${ }^{\mathrm{TM}}$ takes an active learning approach to faculty development. Just as students are used to lectures, so to, faculty are used to workshops. They spend much of their professional lives going to conferences and meetings where they listen to speakers, view power point presentations, and watch demonstrations, etc. Much to the discomfort of some faculty, but to the delight of others, this long-held tradition is not what they encounter in Project LEA/RN ${ }^{\mathrm{TM}}$. From the first day on, faculty are literally up and out of their chairs, experiencing, learning, and reflecting on their teaching practices.

The earlier discussion about the nature of learning and learners suggests that several conditions must be met for learning to occur. In particular, faculty must be given the opportunity to make their basic assumptions explicit, and these assumptions must be challenged. If they are not, no learning will occur. This challenge provides the opportunity for critical reflection and potential reorganization of previously held beliefs about teaching and learning. In short, for change to occur, one must "agitate and educate."

In Project LEA/RN ${ }^{T M}$ this process of agitating and educating proceeds as follows. First, activities are chosen that prompt faculty to 
take a good, hard look at their classroom practices. This may take one of many forms, including: introducing faculty to an interactive strategy (such as TTYP); modeling a pre-post observation conference with a learning partner; or engaging faculty in an experiential learning activity, etc. Following the activity, faculty are invited to reflect on (or in some cases, to agitate over) these experiences and the implications of these experiences for promoting student learning. This "processing time" is done individually at first, and then collectively in a group "go-round" led by a LEA/RN staff facilitator. Faculty opportunity for reflection is then extended once more. At the conclusion of each two hour session, faculty leave with an "assignment" to complete prior to the next meeting. This extended learning opportunity may also take one of many forms, including: trying out a new strategy in class and documenting what happens; meeting with a learning partner to observe each other's class; or preparing a sample lesson to be critiqued by peers at the next meeting, etc. A typical LEA/RN session is described below to further illustrate the process. The session described is the second meeting with faculty.

\section{Session Two}

The session begins with a "go-round." Going around the room, each participant is asked to share one reflection from an assigned reading. This go-round triggers a discussion on the aims of teaching. In particular, this discussion centers on the idea that the espoused goals of faculty frequently do not correspond with actual classroom practice (See Argyris \& Schon in Cranton, 1994). The espoused goals of faculty call for higher order thinking, including such skills as critical thinking, creativity, and problemsolving. Yet, traditional classroom practices typically require of students little more than memory and recall.

This discussion of the consequences of practice continues into the second activity in which faculty share their initial experiences with TTYP. Working with a partner, faculty are asked to answer these three questions: 1) How did students respond to the TTYP; 2) What difficulties, if any, arose as you tried to use it? and 3) What help, if any, do you need to make this strategy more effective or easier for you to 
use? Pairs of faculty share their reflections with the large group for the purpose of feedback and critique.

Beginning in this session and continuing into the third session, faculty watch a videotape that documents some basic, current findings from cognitive research about how students learn. At the same time, faculty are introduced to another interactive strategy, note-taking pairs, which they use while viewing the video.

The session ends with a final go-round and an assignment. In the go-round, faculty share one significant thought from the day's session. In preparation for the next session, they are again asked to try TTYP and note-taking pairs in class and to begin a record of the questions they ask in class.

This description of the LEA/RN process illustrates some of the practices needed to support faculty learning. Activities engage faculty in the concrete tasks of teaching in ways that illuminate the process of learning. Experiences followed by group discussion build natural bridges for critical self-reflection. Moreover, Project LEA/RN ${ }^{\mathrm{TM}}$ recognizes that the hard work of rethinking practice takes time and is nurtured in a climate of trust and support. To this end, staff facilitators continually model strategies, provide constructive feedback, and allow time for faculty to develop and hone new skills. Time is also needed to develop mutual trust and the willingness to take risks. LEA/RN sessions are designed to create a safe space for open and honest dialogue. Finally, Project LEA/RN ${ }^{\mathrm{TM}}$ views faculty development as an ongoing experience. In a sense, participants never "graduate" from Project LEA/RN" ${ }^{\mathrm{TM}}$. Participants are invited to continue in the project semester after semester and year after year (schedules permitting). This ongoing nature provides faculty the opportunity to deepen their knowledge, refine their skills, better integrate the "four thrusts" into practice, and build a sense of community with peers.

\section{Implications for Widespread Change}

Project LEA/RN ${ }^{\mathrm{TM}}$ began in 1994 when 18 faculty members from the Department of Mechanical Engineering linked with a faculty member in the College of Education to better understand the learning and teaching endeavor. As a result of the success of this group, 
excitement about student-centered learning spread, and more faculty asked to be involved. In 1995 two new LEA/RN groups were established. Now in its fourth year, Project LEA/RN ${ }^{T M}$ has grown from 18 faculty to over 180 faculty and has expanded from the College of Engineering to include faculty from nearly all colleges across campus.

The main goal during the first two years of the project was to create a program for faculty based on recent research and theoretical work. This focus continues. In addition, a research component was added during the third year. Data from open-ended questionnaires, interviews, and observations of LEA/RN sessions and faculty classrooms are currently being collected and analyzed to determine the impact of Project LEA/RN ${ }^{\mathrm{TM}}$ on faculty thinking and practice and to examine how faculty come to feel efficacious in aligning their practice with the new paradigm. Preliminary evidence from this work as well as the ten-fold growth of the project suggest that the LEA/RN model is an effective vehicle to support faculty in ways called forth by the paradigm shift. Faculty in the project have adopted new approaches in their classrooms. Furthermore, many have begun to examine and change the underlying assumptions about learning that guide their practice. This evidence suggests that faculty development of this nature can be effective in bringing about change.

Yet, it is within this picture of success that one also catches a glimpse of the challenges posed in bringing about widespread change. The picture painted here is not one of unmitigated success or uniform change. Not all participants make significant changes in practice, and a few faculty drop out of the project for one reason or another. The data we continue to collect may help us understand these findings and shed light on ways the project could be improved to have a broader impact.

Project LEA/RN'M also faces the typical obstacles of time, labor and cost. Sponsored by the College of Engineering and the University's Center for Teaching Excellence, project participants benefit from opportunities and resources not typically provided in faculty development efforts. This suggests that if new visions of classroom practice are to become a reality, we need to rethink our traditional conceptions of faculty development. This is especially true when thinking about the scope of changes desired. The years of growth have 
been both blessing and bane, with enthusiasm of faculty and departments colliding with limitations of time and staff, accentuating the need for ongoing support to sustain such changes.

Why do faculty come? Why do faculty stay? The picture also sheds light on these questions. It is important to remember that participation is voluntary and is based on the premise that faculty want to be effective teachers and will devote time and effort to improve the effectiveness of their teaching. This premise has been borne out time and time again in the lived experience of the project. Faculty have found time-when there was none-to gather together with colleagues, to undertake extended projects, and to attend week-long intensive summer sessions on their own time. They have demonstrated that, given the opportunity, they will make progress in enhancing their teaching effectiveness. One can only guess how results might have been different had participation been mandated.

There are undoubtedly many reasons why faculty stay and why the project has been successful. Two will be suggested here. First, Project LEA $/ \mathrm{RN}^{\mathrm{TM}}$ focuses on learning. The opportunity afforded faculty to examine their own practices and to consider learning as the foundation upon which to frame practice moves teaching beyond technique. Whereas traditional development practices offer faculty tips and strategies, the opportunity to critically reflect on practice and to develop their own epistemic knowledge engages faculty in "the scholarship of teaching." A second and related factor contributing to the impact of Project LEA/RN ${ }^{T M}$ has been its success in legitimating faculty efforts to improve teaching. Prior to getting involved, many faculty had already been involved in efforts to improve student learning. Others, while sensing a need for change, were at a loss for where to begin. In one sense then, Project LEA/RN ${ }^{\mathrm{TM}}$ embodies what these faculty were already about or searching for; in short, faculty feel valued and empowered. In another sense, Project LEA/RN ${ }^{\mathrm{TM}}$ has served as a vehicle for change. By bringing faculty together around a common goal, Project LEA/RN ${ }^{\mathrm{TM}}$ has enabled faculty to forge a collective identity. Together this "community of learners" has taken it upon themselves to further "agitate and educate" for change in their individual departments and across the campus at large. 


\section{Final Thoughts}

The paradigm shift underway in higher education calls for a fundamental change in college instruction. Educational critics and reformers alike view such radical change as necessary for preparing citizens for the 21st century. Yet, these visions and expectations for change cannot rest on the shoulders of individual faculty incorporating new practices into their classrooms. Pedagogical practices and instructor roles are ultimately embedded in institutional cultures. New practices embedded in contexts that are at odds with these new visions are unlikely to take root and grow.

Recognizing the interconnectedness among institutional culture, faculty development, and student development is critical to nurturing new visions. Creating a culture where teaching is valued in higher education will require both new approaches to professional development and new structures to support these approaches. This investment in faculty, in turn, will pay off in gains in student development. Seen from this perspective, faculty development is not a frill, but a necessity.

As faculty focus on students' experiences, drawing on their collective wisdom to solve the problems of practice, new knowledge and understandings are forged. Such activities serve to connect professional learning to collegial learning, creating a collective identity among faculty. It is in this broader identity, this collective strength, wherein the hope of change lies. Working together with a shared sense of purpose, faculty can make a difference in the lives of students, helping them to shape the future of the 21 st century.

\section{References}

Association of American Colleges. (1985). Integrity in the college curriculum: A report to the academic community. Washington DC: Association of American Colleges.

Angelo, T. A., \& Cross, K. P. (1993). Classroom assessment techniques (2nd edition). San Francisco: Jossey-Bass.

Barr, R. B., \& Tagg, J. (1995). From teaching to learning-A new paradigm for undergraduate education. Change, 27(6), 13-25.

Brookfield, S. D. (1988). Adult learners: Motives for learning and implications for practice. In K. A. Feldman \& M. B. Paulsen (Eds.), Teaching and learning in the college classroom (pp. 137-149). Needham Heights, MA: Ginn Press. 
Brookfield, S. D. (1995). Becoming a critically reflective teacher. San Francisco: Jossey Bass.

Campbell, W. E., \& Smith, K. A. (Eds). (1997). New paradigms for college teaching. Edina, MN: Interaction Book Company.

Candy, P. (1991). Self-direction for lifelong learning. San Francisco: Jossey-Bass.

Cranton, P. (1994). Self-directed and transformative instructional development. Journal of Higher Education, 65(6), 726-744.

Gronlund, N. E. (1985). Measurement and evaluation in teaching (5th edition). New York: MacMillan.

Johnson, D. W., Johnson, R. T., \& Smith, K. A. (1991). Active learning: Cooperation in the college classroom. Edina, MN: Interaction Book Company.

Knowles, M. (1984). Andragogy in action: Applying modern principles of adult learning. San Francisco: Jossey-Bass.

Leinhardt, G. (1992). What research on learning tells us about teaching. Educational Leadership, 49(7), 26-29.

Licklider, B. L., Schnelker, D. L. \& Fulton, C. (1998). Revisioning faculty development for changing times: The foundation and framework. The Journal of Staff, Program \& Organization Development, 15(3), 121-134.

Mezirow, J. (1991). Transformative dimensions of adult learning. San Francisco: JosseyBass.

National Science Foundation. (1996). Shaping the future: New expectations for undergraduate education in science, mathematics, engineering, and technology. Report on the Review of Undergraduate Education. Washington, DC: National Science Foundation Directorate for Education and Human Resources.

Study Group on the Condition of Excellence in American Higher Education. (1984). Involvement in learning: Realizing the potential of American higher education. Washington, DC: National Institute of Education, U.S. Department of Education.

Svinicki, M. D. (1991). Practical implications of cognitive theories. In K. A. Feldman \& M. B. Paulsen (Eds.), Teaching and learning in the college classroom (pp. 275-282). Needham Heights, MA: Ginn Press.

von Glaserfeld, E. (1983). Cognition, construction of knowledge, and teaching. Washington, DC: National Science Foundation. (ERIC Document Reproduction Service No. ED 294 754)

\section{Acknowledgments}

This work is supported by the Center for Teaching Excellence, the College of Education, and the College of Engineering at Iowa State. Correspondence concerning this article should be addressed to Barbara Licklider, Educational Leadership and Policy Studies, College of 
Education, Iowa State University, E105 Lagomarcino Hall, Ames, Iowa 50011. Electronic mail may be sent to blicklid@iastate.edu.

\section{Contact:}

Barbara Licklider

Department of Educational Leadership and Policy Studies

College of Education

E 105 Lagomarcino Hall

Iowa Sate University

Ames, IA 50011

(515) 294-1276

(515) 294-0269 FAX

blicklid@iastate.edu

Carol Fulton is Research Coordinator for Project LEA/RN'M. Her areas of expertise include measurement, research, and evaluation. She is completing a $\mathrm{PhD}$ in Research and Evaluation. Her current interest is the history of American Higher Education.

Barbara Licklider is an Associate Professor in the Educational Leadership and Policy Studies Department at Iowa State and has received numerous awards for teaching excellence. Her specific areas of interest include active learning and learning enhancement for undergraduates, school transformation, and staff development for effective teaching. She is Director of Project LEA/RN'T 


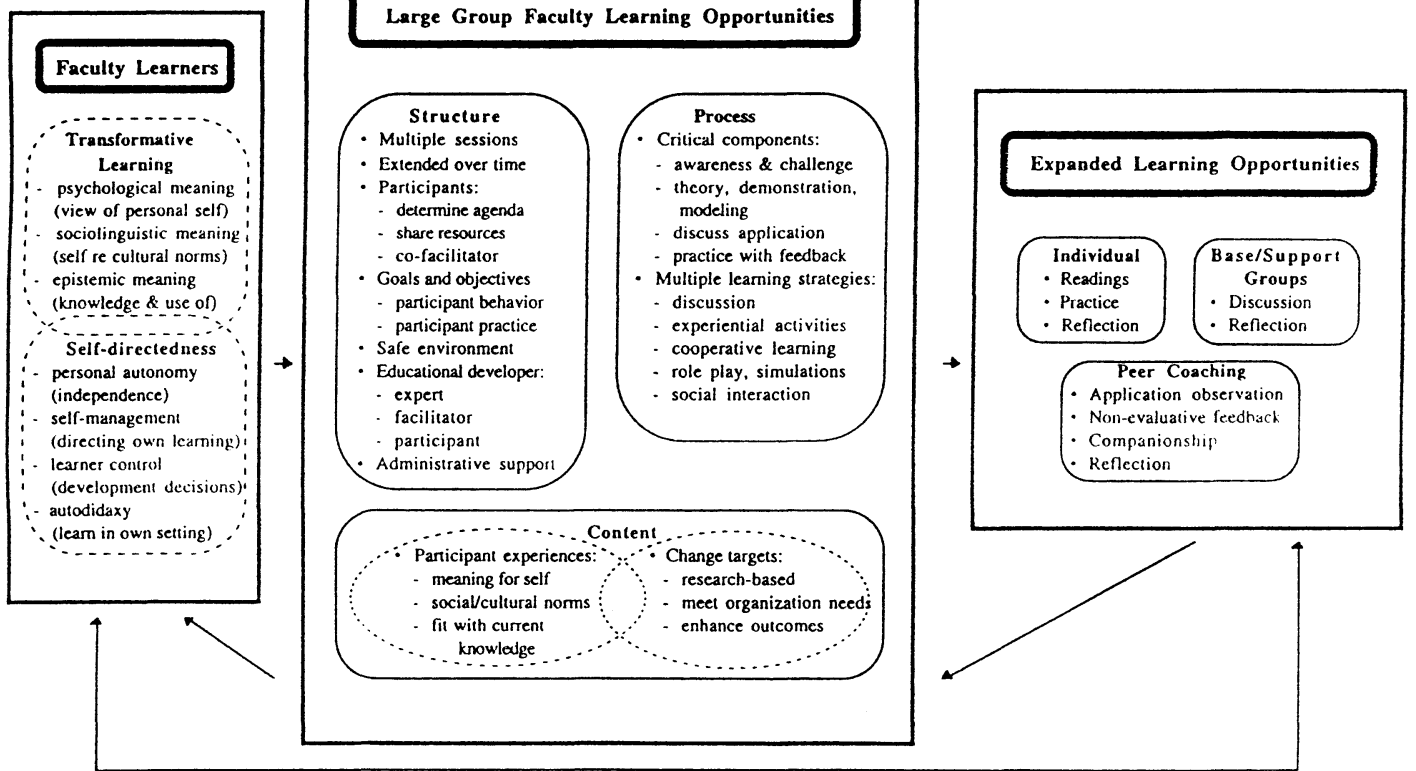

